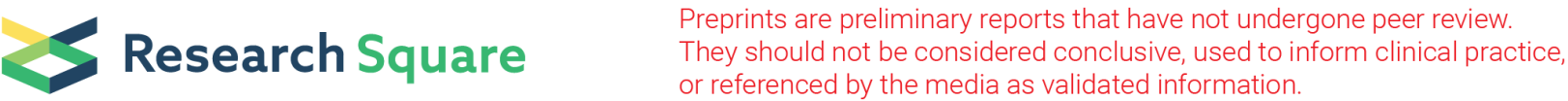 \\ Study on Hole Making Process of Thick-section Carbon Fiber Reinforced Plastics
}

\section{Jianping Li}

University of Science and Technology Liaoning https://orcid.org/0000-0002-6302-999X

Anyuan Jiao ( $\nabla$ jay@ustl.edu.cn )

College of Mechanical Engineering and Automation, University of Science and Technology Liaoning, Anshan 114041, China

\section{Xiaomei Chen}

College of Mechanical Engineering and Automation, University of Science and Technology Liaoning, Anshan 114041, China

\section{Research Article}

Keywords: Helical milling, Orthogonal experiment, Variable parameters, Step-by-step hole making

Posted Date: April 28th, 2021

DOI: https://doi.org/10.21203/rs.3.rs-353642/v1

License: (1) (1) This work is licensed under a Creative Commons Attribution 4.0 International License. Read Full License 


\title{
Study on hole making process of thick-section Carbon Fiber
}

\section{Reinforced Plastics}

\author{
Jianping Li ${ }^{1}$, Anyuan Jiao ${ }^{1,}$, , Xiaomei Chen ${ }^{1}$ \\ 1 College of Mechanical Engineering and Automation, University of Science and Technology Liaoning, Anshan \\ 114041, China \\ * $\quad$ Correspondence: jay@ustl.edu.cn
}

\begin{abstract}
In this paper, the mechanism of helical milling was analyzed at first. Then, the orthogonal experiments on the $24 \mathrm{~mm}$ thick carbon fiber reinforced composite material (CFRP) that affect the quality of hole making, such as spindle speed, feed per tooth, and number of tool's blades were conducted. The influence of process parameters on the quality of hole making was analyzed. Finally, the range analysis method was used to obtain the best hole-making parameters: spindle speed is 4500rpm, feed per tooth is $0.02 \mathrm{~mm} / \mathrm{z}$, the number of tool's blades is 2 . Based on the obtained optimal parameters, the step-by-step hole making of thick-section CFRP with variable parameters was studied, and two sets of parameters were designed. Through the measurement of the hole morphology, roughness, axial force and aperture deviation after the experiment, it is concluded that hole making process with variable parameters can meet the technical requirements of thick-section CFRP.
\end{abstract}

Key words: Helical milling; Orthogonal experiment; Variable parameters; Step-by-step hole making

\section{Introduction}

CFRP has been widely used in the main bearing structure of large aircraft due to the advantages of high specific strength, high specific modulus, good rigidity, small specific gravity, good fatigue resistance, high temperature resistance, corrosion resistance, and wear resistance [1-3]. In order to meet the assembly requirements between the CFRP main loadbearing components in large aircraft, a large number of riveting and bolt connections are required. Therefore, the hole making process is the most commonly used processing technology in the manufacture of CFRP structural parts [4]. There has been a long period of research on CFRP around the world. Koplev et al. proposed for the first time that the fiber and matrix fracture caused the formation of chips through a series of unidirectional carbon fiber composite cutting tests. This is also the most recognized theory in the industry at this stage [5]. Zhang L et al. used the drill bit of different structure to study the hole making of CFRP/Al laminated material, and the law of the influence of the tool on the hole making quality has been obtained [6]. Qiu X et al. studied the influence of processing parameters and drill bit geometry on cutting force and hole wall damage [7]. Wang XD et al. processed large thick-section CFRP with variable parameters, which effectively reduced the cutting heat and axial force, and improved the quality of hole making [8].

Compared with the traditional drilling process, helical milling adopts eccentric processing, which eliminates the effect of the traditional twist drill chisel edge, reduces the axial force, and greatly improves the processing quality. Wangyang $\mathrm{N}$ et al. studied the mechanism of helical milling, analyzed the influence of cutting amount on cutting force during helical milling process, and proved the advantages of helical milling in CFRP/alloy laminated structure hole making [9]. Qin XD et al. systematically explained the advantages of helical milling technology over traditional drilling technology, and predicted the development and application of helical milling technology in the aviation manufacturing industry [10]. Wang Q et al. proposed a new process called oblique helical milling based on helical milling for high-quality CFRP hole making [11]. Sha ZH et al. designed a helical milling end execution that can be used in a robotic hole making system. It improves the automation degree and production efficiency of helical milling [12].

There are more problems and defects in hole making on the thick-section CFRP than on the conventional thickness CFRP. In this paper, the mechanism of helical milling was studied, orthogonal experiments were designed, the results were measured to analyze the influence of different processing parameters on the quality of hole making. The best hole making parameters was found, and on this basis, some researches on helical milling of thick-section CFRP with variable parameters were carried out. 


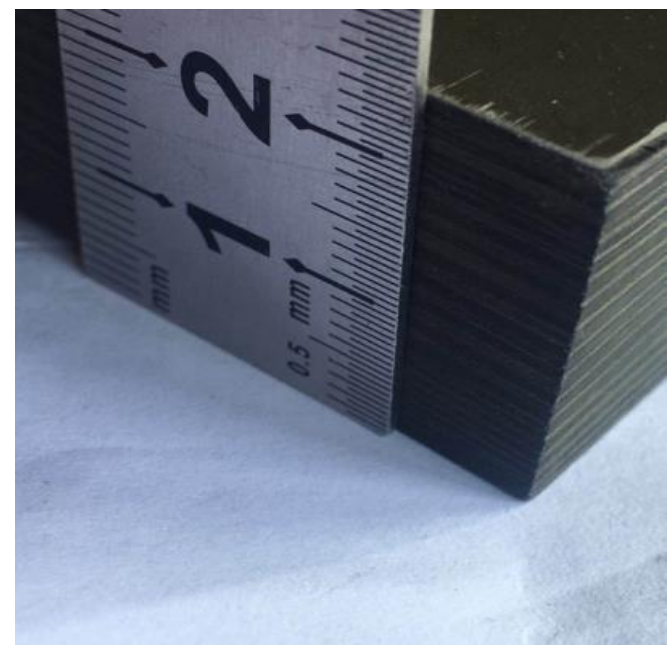

Figure $124 \mathrm{~mm}$ CFRP material

\section{Research on Milling Mechanism}

Helical milling is a brand-new hole making method based on the milling machine processing method. On the CNC milling machine, the helical feed motion is composed of two independent motions, including the rotary motion of the tool around the axis of the machined hole is called revolution motion, and the linear feed motion of the tool along the axis is called axial feed motion. In addition, the tool itself rotates at a high speed, that is the main cutting motion, also known as the rotation motion [13].

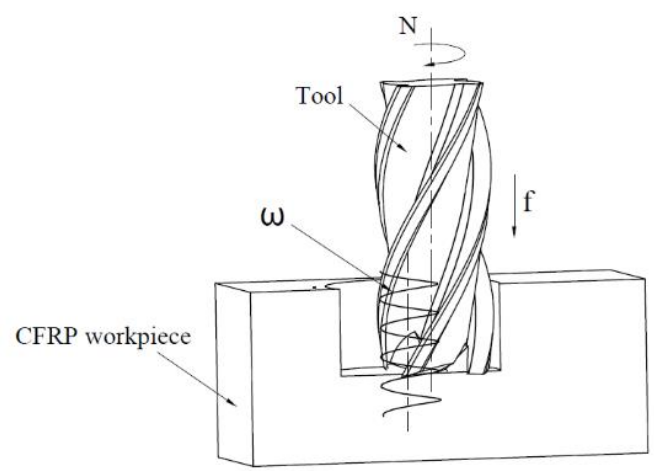

Figure 2 Schematic diagram of helical milling
The plan schematic diagram of helical milling is shown in Figure 3.

The main parameters shown in Figure 2 and Figure 3 are: spindle speed - N, helical speed $\omega$, axial feed $-f$, eccentricity - e, aperture - D, tool's diameter - $d$, pitch - a and the number of blades(teeth) $-Z_{n}$. It can be seen from the figures that the pitch is:

$a=f / \omega$

And can be seen from the geometric relationship that:

$$
\tan \beta=\frac{a}{\pi(D-d)}
$$

According to formula (1) and formula (2):

$$
\beta=\arctan \frac{f}{\pi \omega(D-d)}
$$

In helical milling, the axial feed - a is small. When the helix angle $\beta$ is very small, $\tan \beta \approx \beta$, then:

$$
\beta \approx \frac{f}{\pi \omega(D-d)}
$$

The hypotenuse of the right-angled triangle in Figure 3 is the length of the milling line. During the cutting process, the amount of material removal - $\Psi$ can be expressed as:

$$
\Psi=\frac{f /(\omega \sin \beta)}{N Z} \times \omega=\frac{f}{N Z \sin \beta}
$$

When the helix angle $\beta$ is very small, $\sin \beta \approx$ $\beta$. Substituting formula (4) into formula (5):

$$
\Psi=\frac{f}{N Z} \times \frac{\pi \omega(D-d)}{f}=\frac{\pi \omega(D-d)}{N Z}
$$

It can be seen from formula (6) that the material cutting amount - $\Psi$ is inversely proportional to the spindle speed - N. When the spindle speed increases, the material cutting amount decreases, and the cutting force also decreases accordingly.

According to theoretical analysis, the selection of technological parameters for experimental research is: spindle speed, feed per tooth and number of blades.

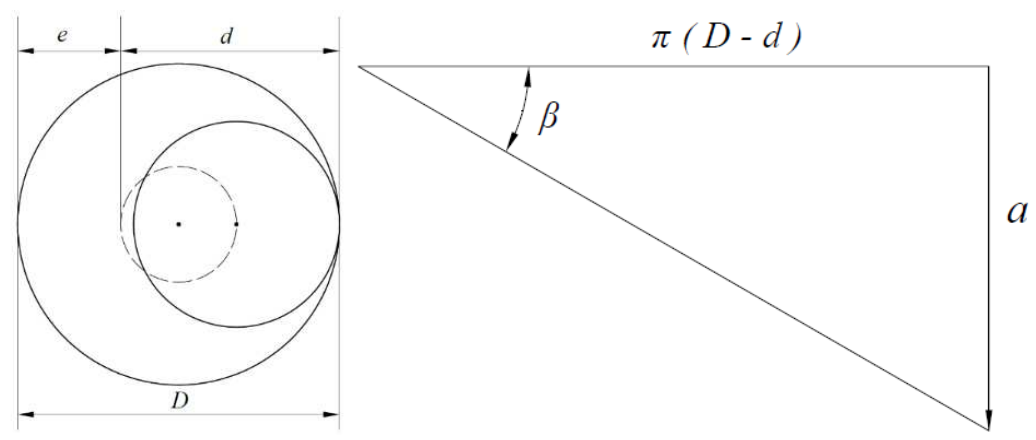

Figure 3 Plan schematic diagram 


\section{The experiment of helical milling}

\subsection{Experimental conditions}

The material selected for this experiment is CFRP, the thickness is $24 \mathrm{~mm}$, the diameter of the milling cutter used is $6 \mathrm{~mm}$, and the diameter of the hole is $8 \mathrm{~mm}$.

\subsection{Experimental design}

Orthogonal experiment is a method to deal with multi-factor and multi-level experiments [14]. This paper uses orthogonal experiment method to design the experiment. Through the experiment and consulting related materials, it is found that the main factors affecting the quality of hole making are the speed of the tool, the amount of feed, and the tool parameters. This article selects the spindle speed - N, feed per tooth - $f_{z}$, and the number of blades $-Z_{n}$ as the experimental factors, which have a direct effect on the axial force. Among them, the spindle speed and the feed per tooth select 4 levels, and the number of blades choose 3 levels. This experimental program adopts the orthogonal table design without interaction, and adopts the similar concept of the quasi-level method [15]. The threefactor four-level orthogonal table was listed first, and then eliminate all groups with 4 in the third factor (number of blades). The factor level table is shown in Table 1.

Table 1 Factor level table

\begin{tabular}{cccc} 
Fevel & $\begin{array}{c}\text { Feed per tooth } \\
(\mathrm{mm} / \mathrm{z})\end{array}$ & $\begin{array}{c}\text { Number of blades } \\
1\end{array}$ \\
2 & 3000 & 0.02 & 2 \\
3 & 4000 & 0.03 & 3 \\
4 & 4500 & 0.04 & 4 \\
\hline
\end{tabular}

The orthogonal experiment table was designed, and the data of the axial force during the helical milling process was recorded, as shown in Table 2.

\begin{tabular}{|c|c|c|c|c|}
\hline $\mathrm{No}_{\text {No }}^{\text {Factor }}$ & $\begin{array}{c}N \\
(r p m) \\
\end{array}$ & $\begin{array}{c}f_{z} \\
(\mathrm{~mm} / \mathrm{z})\end{array}$ & $Z_{n}$ & $\begin{array}{l}F_{z} \\
(N) \\
\end{array}$ \\
\hline 1 & 2000 & 0.02 & 2 & 88.7885 \\
\hline 2 & 2000 & 0.03 & 3 & 146.7308 \\
\hline 3 & 2000 & 0.04 & 4 & 175.0962 \\
\hline 5 & 3000 & 0.02 & 3 & 75.7169 \\
\hline 6 & 3000 & 0.03 & 2 & 150.9038 \\
\hline 8 & 3000 & 0.05 & 4 & 179.1509 \\
\hline 9 & 4000 & 0.02 & 4 & 86.6667 \\
\hline 11 & 4000 & 0.04 & 2 & 146 \\
\hline 12 & 4000 & 0.05 & 3 & 152.9623 \\
\hline 14 & 4500 & 0.03 & 4 & 106.6154 \\
\hline 15 & 4500 & 0.04 & 3 & 96.0943 \\
\hline 16 & 4500 & 0.05 & 2 & 139.3269 \\
\hline
\end{tabular}

The resultant force of the workpiece in the $\mathrm{X}$-axis and $\mathrm{Y}$-axis directions is the radial force.
Through the comparison and calculation of the force change curve collected by the three-axis 
force sensor, it can be obtained that the radial force generated during the thick-section CFRP hole making process is very small, and the largest group is $35.35 \mathrm{~N}$, which accounts for about $20 \%$ of the axial force of $Z$-axis, so the next hole making experiment only needs to consider the influence of the axial force of $\mathrm{Z}$ axis.

\subsection{Data analysis}

The purpose of processing the obtained experimental data is to determine the optimal level of each experimental factor and the optimal combination within the experimental range, and to determine the primary and secondary relationship between the experimental factors. The first is the direct comparison method. This method simply compares the experimental results, which is in line with people's conventional cognition. Although the direct comparison method provides a certain description of the test results, this description is qualitative and cannot certainly tell us whether the best combination is included in the above experiment. So we use the second method which called the range analysis method. This method can analyze the test results intuitively and determine the priority and optimal combination of each experimental factor.

In the range analysis method, $R_{j}$ is the range of $\mathrm{j}$ factor, and its calculation formula can be defined as follows:

$$
R_{j}=\max \left[\overline{y_{J 1}}, \overline{y_{J 2}}, \ldots\right]-\min \left[\overline{y_{J 1}}, \overline{y_{J 2}}, \ldots\right]
$$

Among them, $\mathrm{y}_{\mathrm{jk}}$ is the sum of experimental indicators corresponding to $\mathrm{j}$ factor and $\mathrm{k}$ level, $\overline{y_{j k}}$ is the average of $\mathrm{y}_{\mathrm{jk}}$. The size of $\overline{y_{j k}}$ can judge the optimal level of $\mathrm{j}$ factor and its optimal combination. $\mathrm{R}_{\mathrm{j}}$ reflects the fluctuation range of the experimental index when the factor level of the j-th column fluctuates. The larger the $\mathrm{R}_{\mathrm{j}}$, the greater the influence of the experimental factor on the index. Therefore, according to the value of $R_{j}$, the primary and secondary order of the influence of factors on experimental indicators can be judged.

Due to the inconsistent levels of the factors selected in the orthogonal table, the range value needs to be calculated by the conversion coefficient method, and the calculation is shown in formula (8):

$$
R^{\prime}=\frac{d_{i}}{\sqrt{r_{i}}} \times R
$$

The value of the conversion coefficient $\mathrm{d}_{\mathrm{i}}$ in the formula is shown in Table 3.

Table 3 Conversion coefficient table

\begin{tabular}{cccccccc}
\hline $\begin{array}{c}\text { Number of levels } \\
i\end{array}$ & 2 & 3 & 4 & 5 & 6 & 7 & 8 \\
\hline$d_{i}$ & 0.71 & 0.52 & 0.45 & 0.40 & 0.37 & 0.35 & 0.34 \\
\hline
\end{tabular}

The range $\mathrm{R}$ of the sum of the experimental levels can be calculated by the range $\bar{R}$ of its average. Since $R=r_{i} \bar{R}$, it was put into formula (8),

$$
R^{\prime}=\sqrt{r_{i}} \times d_{i} \times \bar{R}
$$

In the formula:

$\mathrm{R}^{\prime}$-conversion range; $\mathrm{d}_{\mathrm{i}}$-conversion coefficient; i-the number of levels; $r_{i}$-the number of repetitions at each level.

The range value of the range analysis method in this paper needs to be corrected by formula (9). The range analysis method was used to analyze the axial force, as shown in Table 4.

Table 4 Axial force range analysis table

\begin{tabular}{ccccc} 
Spindle speed & $\begin{array}{c}\text { A } \\
(\mathrm{rpm})\end{array}$ & $\begin{array}{c}\text { Feed per tooth } \\
(\mathrm{mm} / \mathrm{z})\end{array}$ & $\begin{array}{c}\text { Number of blades } \\
\text { Axial force }\end{array}$ \\
\hline 1 & 2000 & 0.02 & 2 & 138.7885 \\
2 & 2000 & 0.03 & 3 & 146.7308 \\
3 & 2000 & 0.04 & 4 & 175.0962 \\
5 & 3000 & & 3 & 75.7169 \\
6 & 3000 & 0.02 & 2 & 110.9038
\end{tabular}




\begin{tabular}{ccccc}
8 & 3000 & 0.05 & 4 & 179.1509 \\
9 & 4000 & 0.02 & 4 & 86.6667 \\
11 & 4000 & 0.04 & 2 & 106 \\
12 & 4000 & 0.05 & 3 & 152.9623 \\
14 & 4500 & 0.03 & 4 & 106.6154 \\
15 & 4500 & 0.04 & 3 & 96.0943 \\
16 & 4500 & 0.05 & 2 & 99.3269 \\
$\overline{y_{J 1}}$ & 153.5385 & 100.3907 & 113.7548 & \\
$\overline{y_{j 2}}$ & 121.924 & 121.4167 & 117.8760 & \\
$\overline{y_{j 3}}$ & 115.21 & 125.7302 & 136.8823 & \\
$\overline{y_{j 4}}$ & 100.6789 & 143.8134 & & \\
$R_{j}$ & 52.8596 & 43.4227 & 23.1275 & \\
$R_{j}^{\prime}$ & 41.1999 & 33.8446 & 24.0526 & \\
\hline
\end{tabular}

The analysis of $\overline{y_{I k}}$ in the table shows that for the spindle speed, $\overline{y_{A 4}}<\overline{y_{A 3}}<\overline{y_{A 2}}<$ $\overline{y_{A 1}}$, indicating that the axial force is smallest when the spindle speed is $4500 \mathrm{rpm}$. For the feed per tooth, $\overline{\boldsymbol{y}_{B 1}}<\overline{\boldsymbol{y}_{B 2}}<\overline{\boldsymbol{y}_{B 3}}<\overline{\boldsymbol{y}_{B 4}}$ which indicates that when the feed per tooth is $0.02 \mathrm{~mm} / \mathrm{z}$, the axial force is smallest. For the number of blades, $\overline{y_{C 1}}<\overline{\boldsymbol{y}_{C 2}}<\overline{\boldsymbol{y}_{C 3}}$, it means that when the number of blades is 2 , the axial force is the smallest. The analysis of the range $\mathrm{R}_{\mathrm{j}}$ shows that the spindle speed, the feed per

\section{The experiment of hole making with variable parameters}

\subsection{Experimental design}

Based on the conclusion of orthogonal experiment, this chapter takes the improvement of the quality of the entrance and exit of the hole as the experimental goal, using a 2-blades tool, and planning a hole making scheme with variable parameters, as shown in Figure 4. When the tool is close to the surface of the workpiece to the depth of $8 \mathrm{~mm}$, parameter 1 is used for processing; when the tool is to make a hole in the workpiece at a depth of $8-16 \mathrm{~mm}$, parameter 2 is used, and from $16 \mathrm{~mm}$ to the completion of the hole, parameter 3 is used. Two sets of experimental studies were carried out under the cutting process parameters shown in Table 5, tooth and the number of blades all have effects on the axial force. Among them, the spindle speed has the greatest influence and the number of blades has the least influence.

To sum up, when the spindle speed is $4500 \mathrm{rpm}$, the feed per tooth is $0.02 \mathrm{~mm} / \mathrm{z}$, and the number of blades is 2, the axial force is the smallest. That is, $\mathrm{A}_{4} \mathrm{~B}_{1} \mathrm{C}_{1}$ is the best parameter combination for machining thick-section CFRP with helical milling.

with 5 holes in each group, and the influence of hole making with various parameters scheme on the quality of the holes was analyzed.

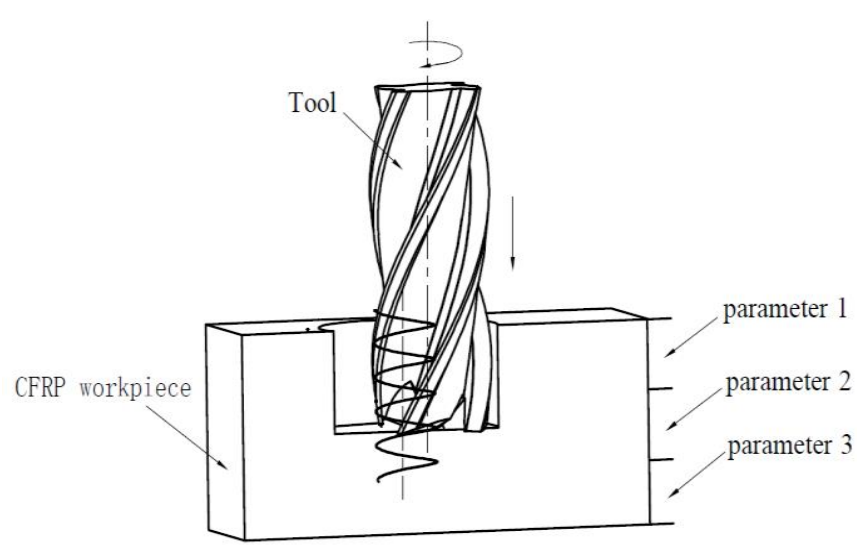

Figure 4 Schematic diagram of helical milling with various parameters 
Table 5 Parameters of step-by-step hole making

\begin{tabular}{cccc}
\hline Group & Sep & Spindle speed $(\mathrm{rpm})$ & $\begin{array}{c}\text { Feed per tooth } \\
(\mathrm{mm} / \mathrm{z})\end{array}$ \\
& & & 0.02 \\
1 & Step 1 & 2000 & 0.04 \\
& Step 2 & 2000 & 0.02 \\
\hline \multirow{2}{*}{2} & Step 3 & 4500 & 0.02 \\
& Step 1 & 2000 & 0.04 \\
& Step 2 & 4500 & 0.02 \\
\hline
\end{tabular}

\subsection{Result analysis}

\subsubsection{Analysis of surface quality and axial} force

The increase of the spindle speed can reduce the axial force, so the quality of the processed hole is improved, but the high speed will cause the hole diameter deviation too large which cannot meet the accuracy requirements.

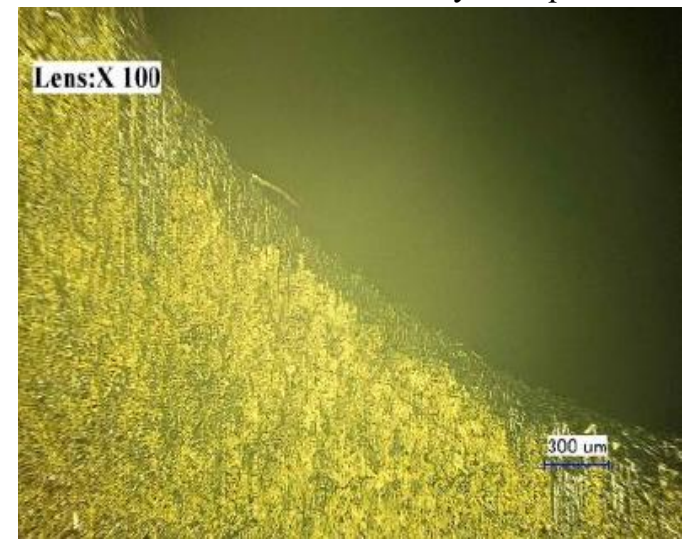

The entrance of the first set

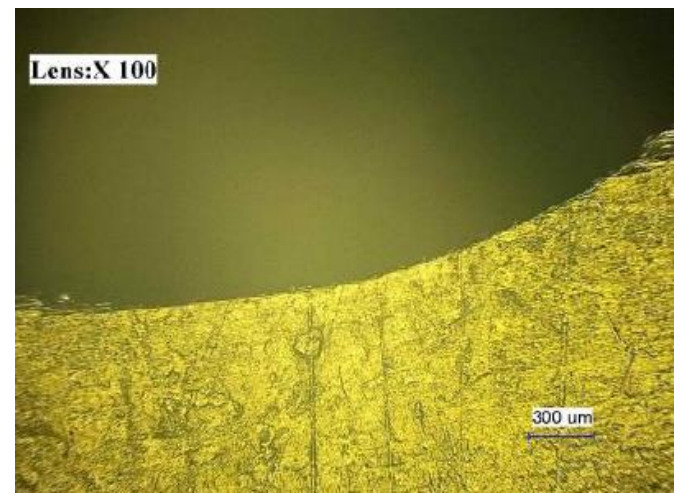

The outlet of the first set

Figure 5 The morphology of entrance and outlet

It can be seen from Figure 5 that the quality at the exit of the hole is slightly better than the quality at the entrance, and there is no burr delamination. This is because the exit speed is
Considering the problem of aperture deviation, the machining hole too large or too small also unable to meet the requirements of assembly accuracy. For this reason, the experimental method with various parameters was set up. The microscopic morphology of the holes processed were observed, and the morphology of the entrance and outlet of the obtained hole is shown in Figure 5.

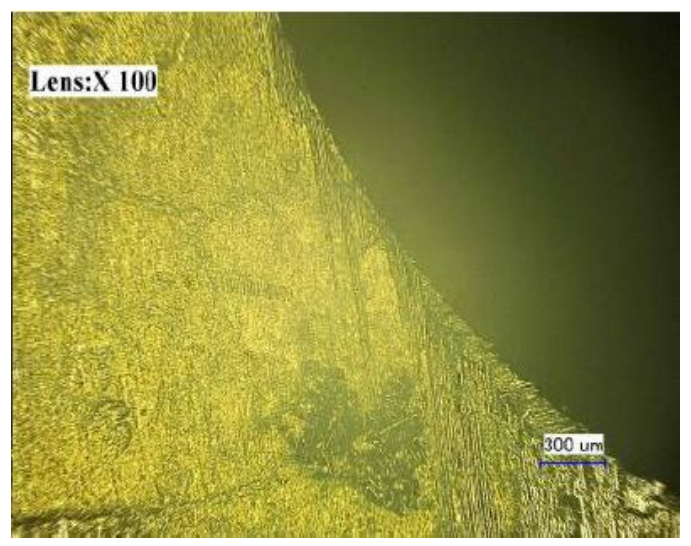

The entrance of the second set

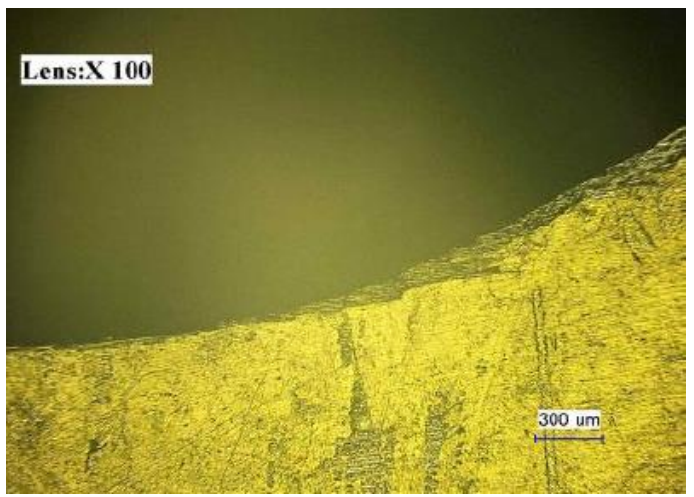

The outlet of the second set

higher than the entrance, so the quality of the exit will be higher than the quality of the hole processed at the same speed. The quality of the holes at the entrance and the exit of two sets of 
experiments is not much different. This is because the two sets of experiments have the same speed at the entrance and the same speed at the exit. The step-by-step hole making experiment can not only meet the requirement of not too high rotation speed at the entrance, but also meet the requirement of reducing burrs, tears and other damages at the exit.

Figure 6 is the curve of the hole wall morphology and surface roughness corresponding to the typical holes ( $\mathrm{Ra}$ is the largest of 5 holes ) of the two sets of experiments, and Figure 7 shows the measured axial force curve after the experiment.

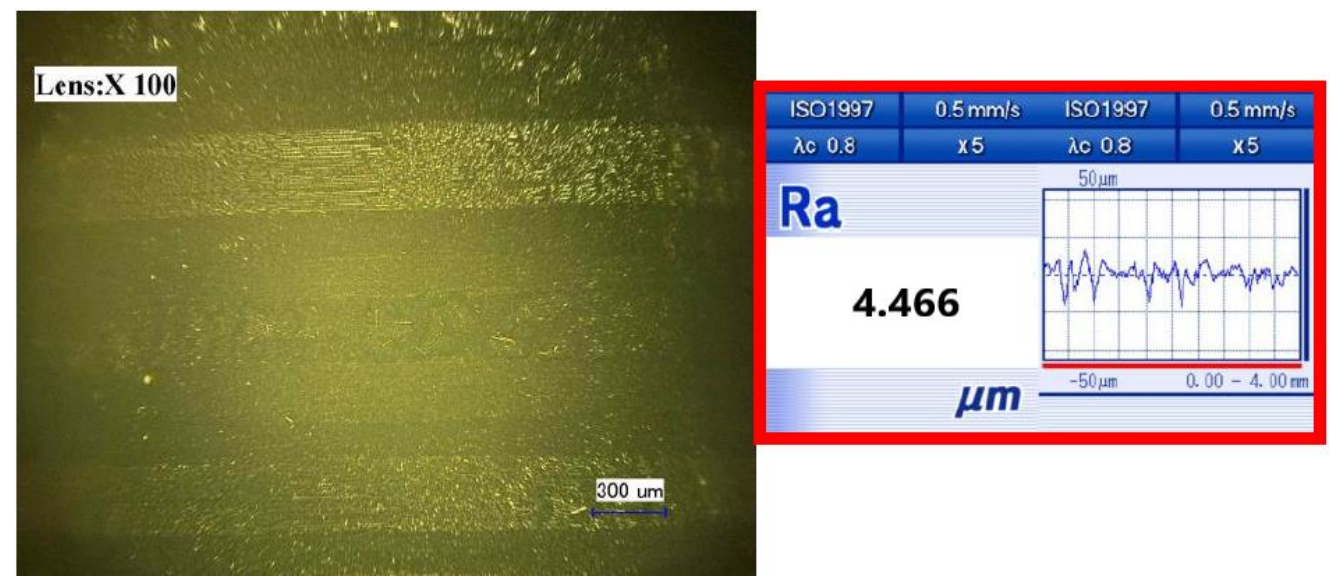

a. First set

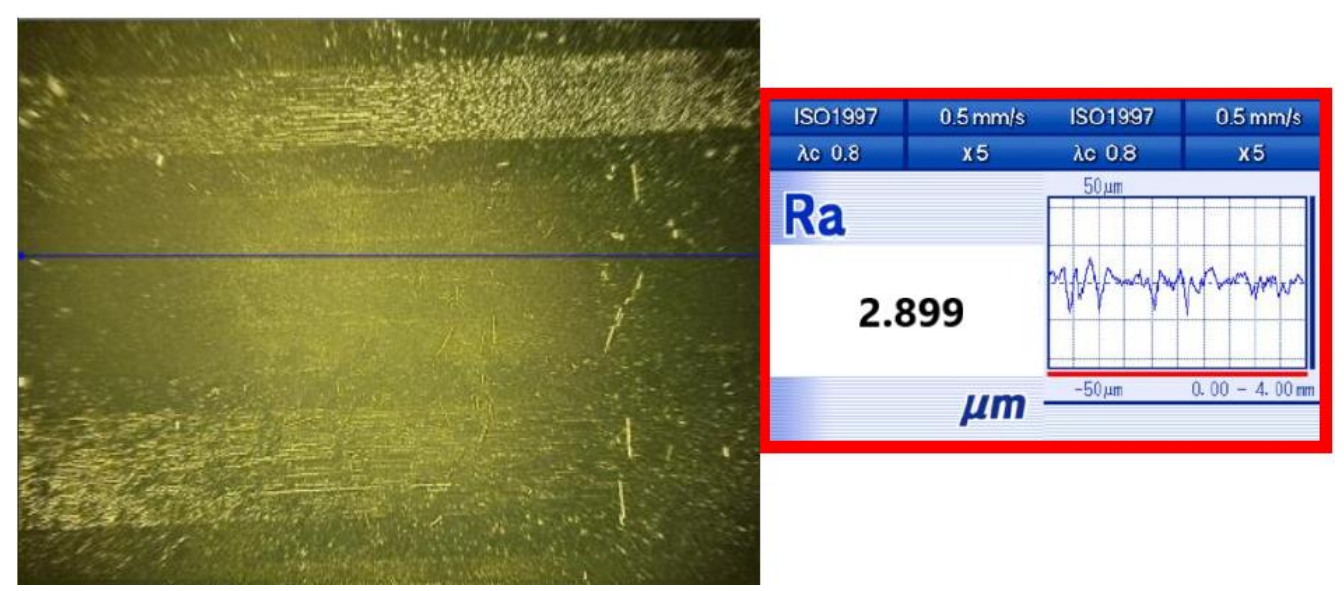

b. Second set

Figure 6 The curve of the hole wall morphology and surface roughness

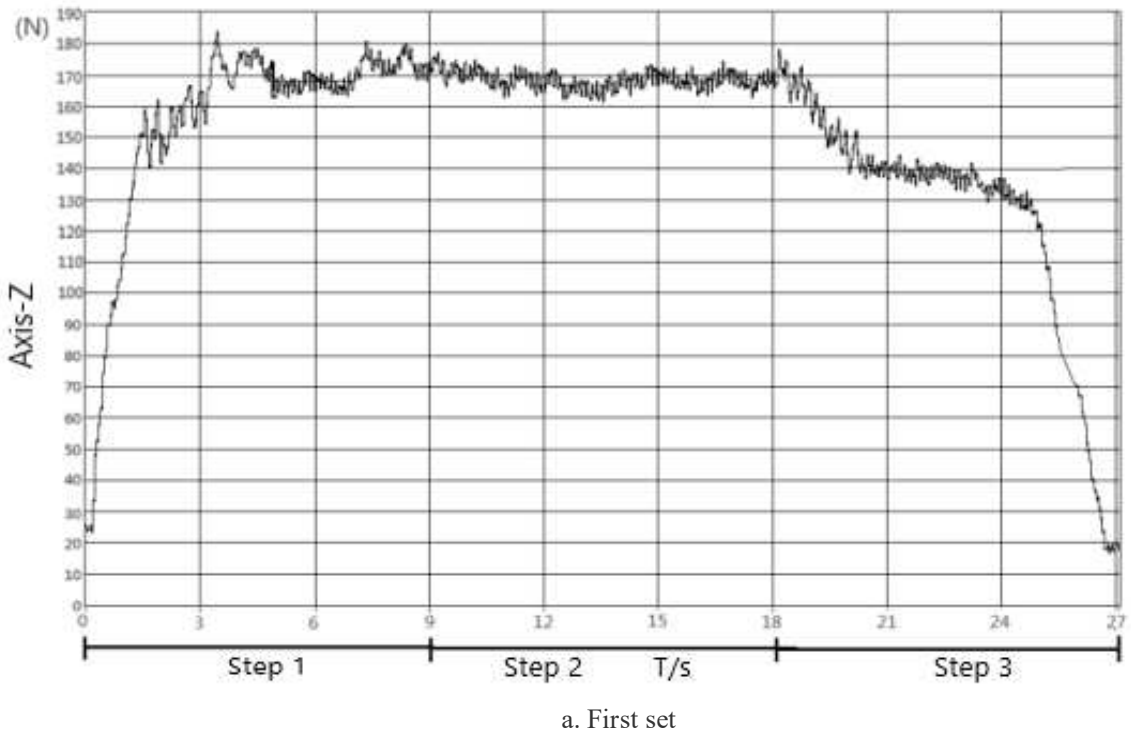




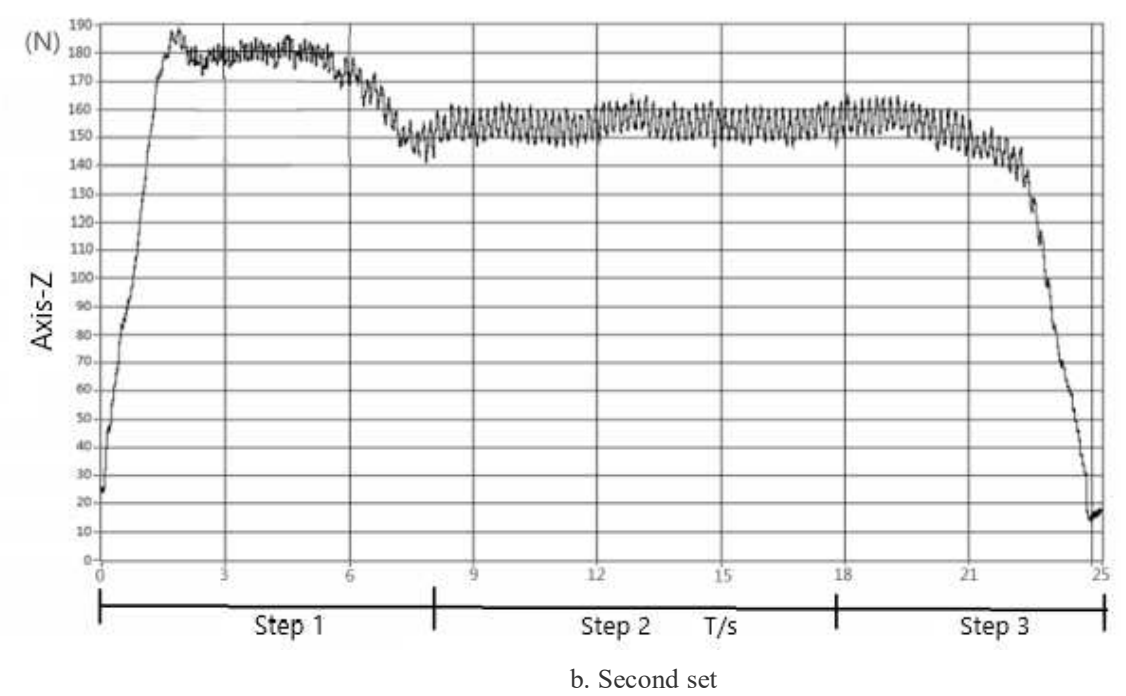

Figure 7 The curve of the axial force

It can be seen from Figure 6 that after magnification of 100 times, the hole wall of the first set has gullies and scratches, and the surface roughness is 4.466 , which does not meet the hole wall roughness requirements, as shown in Figure 6(a). Compared with the first hole, the wall of the second set is smoother, and the surface roughness is 2.899 , which meets the requirements of hole wall roughness. This is caused by the axial force change during the hole machining process. As shown in Figure 7, when the hole is processed to the step 2, for the first step, the axial force in the middle of the hole is basically maintained at about $145 \sim 155 \mathrm{~N}$, while the axial force in the middle of the second set is basically stable at $120 \mathrm{~N}$. The fluctuation range of first set is relatively large, so the surface roughness value of the prepared hole is relatively high, and the quality of the hole is relatively poor. Since the selection of parameters of step-by-step experiment is irregular, the roughness of the hole is too large. These parameters can be used as a reference to process the hole which meet the roughness requirements on thick-section CFRP.

\subsubsection{Analysis of aperture deviation}

The use of this scheme can effectively avoid the problem of aperture deviation caused by excessively high speed. Under the two sets of parameters hole making scheme, 5 holes were processed each, the diameters of the holes at the entrance ( $3 \mathrm{~mm}$ away from the entrance), middle and exit ( $3 \mathrm{~mm}$ away from the exit) were measured and compared with the theoretical value, the aperture deviation is shown in Figure 8. It can be seen that the hole-making with various parameters effectively reduces the aperture deviation, and the deviation at the entrance, exit and the middle part is significantly reduced from before. The two sets of holes' apertures have little difference at the entrance. This is because the rotation speed and feed rate at the entrance is the same as that at the exit. However, there are some changes in the middle because of a sudden change in the rotation speed, but they all meet the accuracy requirements, and the deviation can be controlled between $-0.05 \sim 0.1$. It can be seen that the step-by-step scheme is of great help to reduce the aperture deviation.

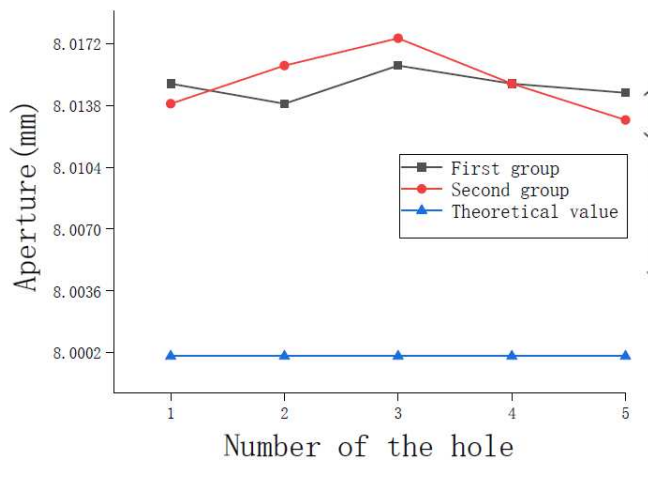

a. The entrance of the hole

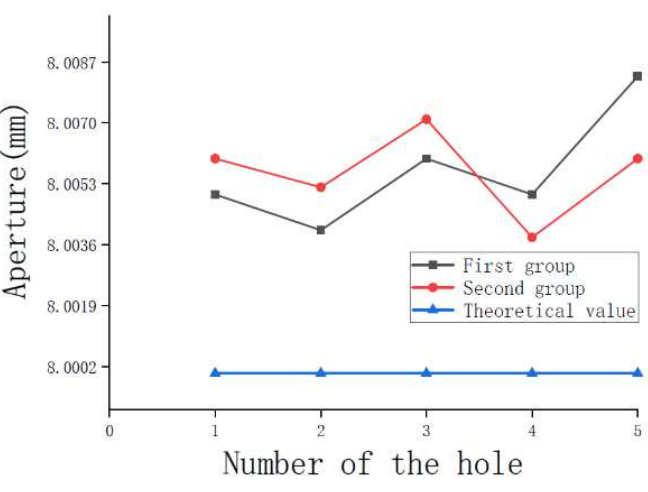

b. The outlet of the hole 


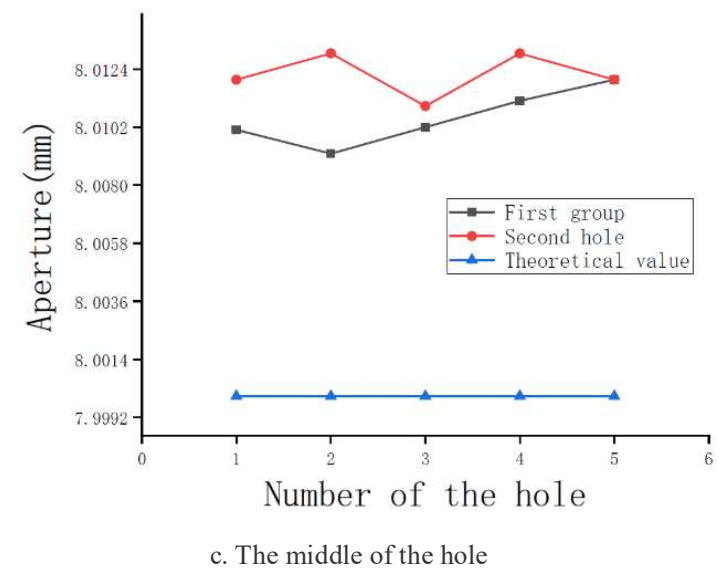

Figure 8 Pore size distribution diagram of step-by-step parameter hole making

After calculating the average deviation of aperture, the histogram of the deviation rate of

step-by-step hole making is shown in Figure 9.

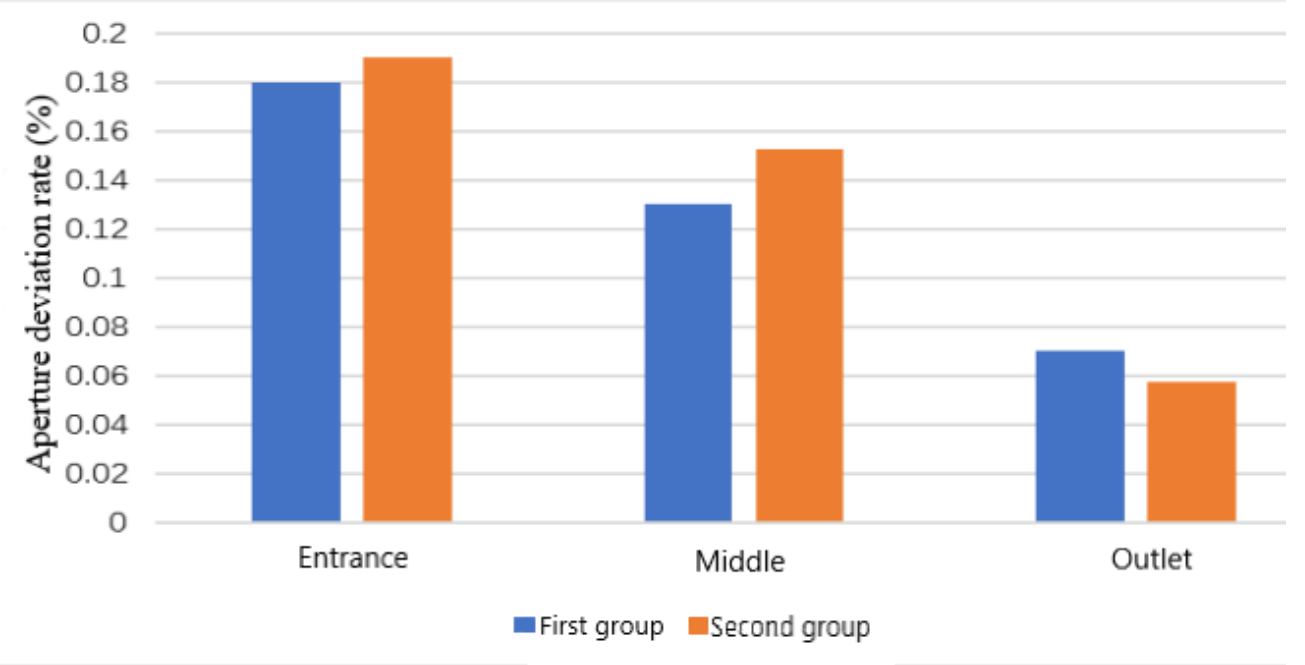

Figure 9 The histogram of the deviation rate of step-by-step hole making

In this figure, the aperture deviation rate of two sets of entrances, outlets and middle of experimental holes can be seen more clearly and intuitively. Compared with other previous schemes, the step-by-step hole making scheme can effectively reduce the overall aperture deviation and control the aperture deviation rate within $0.2 \%$.

From a comprehensive point of view, the use of step-by-step method for thick-section CFRP is helpful to improve the quality of hole making. This method can not only reduce the large aperture deviation at the entrance of the hole due to excessive speed, but also improve the phenomenon such as cracks and burrs at the exit. At the same time, more reasonable parameters can be selected to improve the layering and roughness of the hole wall.

\section{Conclusion}

(1) The experimental plan was designed by orthogonal experiment, and the results were analyzed by range analysis method. The best parameters for helical milling holes of thicksection CFRP (24mm thickness) were obtained: spindle speed is $4500 \mathrm{rpm}$, feed per tooth is $0.02 \mathrm{~mm} / \mathrm{z}$ and the number of blades is 2 .

(2) On the basis of the best parameters obtained in the conclusion (1), the step-by-step hole making of thick-section CFRP with variable parameters was studied, and two sets of parameters were designed. After the experiment, the entrance, exit and hole wall of the hole were studied. The measurement and analysis of the morphology, hole wall roughness, axial force change and hole diameter deviation show that the step-by-step scheme is helpful to improve the quality of hole making. This method can not only reduce the large aperture deviation at the entrance of the hole due to excessive speed, but also improve the phenomenon such as cracks and 
burrs at the exit. At the same time, more reasonable parameters can be selected to improve the layering and roughness of the hole wall.

\section{Nomenclature}

$\mathrm{N}$ - Spindle speed (rpm)

$f$ - Axial feed ( $\mathrm{mm} / \mathrm{min})$

$\omega$ - Helical speed (rpm)

e - Eccentricity (mm)

D - Aperture (mm)
$Z_{n}$ - The number of blades

$\beta$ - Helix angle $\left(^{\circ}\right)$

$\Psi$ - The amount of material removal (mm)

$f_{z}$ - Feed per tooth $(\mathrm{mm} / \mathrm{z})$

$F_{z-}$ Axial force $(\mathrm{N})$

$\mathrm{y}_{\mathrm{jk}}$-The sum of indicators corresponding to $\mathrm{j}$ factor and $\mathrm{k}$ level

$R_{j}$ - The range of $j$ factor

$i$ - The number of levels

$\mathrm{R}^{\prime}$ - Conversion range

$r_{i}$ - The number of repetitions at each level

$d_{i}$ - Conversion coefficient

$\mathrm{Ra}$ - Roughness $(\mu \mathrm{m})$

\section{Declarations}

Funding This paper was funded by the Natural Science Foundation of Liaoning Province Grant (no.2019-ZD-0029) and the University of Science and Technology Liaoning Talent Project Grants (no.601011507-32). the sum of indicators corresponding to $\mathrm{j}$ factor and $\mathrm{k}$ level

Competing interests The authors declare no competing interests.

Availability of data and material Not
applicable.

\section{Code availability Not applicable.}

Authors' contributions Determine the research direction and list the outline: Anyuan Jiao; Study on the mechanism: Jianping Li; Experiment and data analysis: Xiaomei Chen and Jianping $\mathrm{Li}$; original draft preparation: Jianping Li.

\section{Ethics approval Not applicable.}

Consent to participate Not applicable.

Consent for publication Not applicable.

\section{References}

【1】 Liu DF, Tang YJ, Cong WL (2012) A review of mechanical drilling for composite laminates. Composite Structures 94(4):12651279.

【2】Chen $\mathrm{Y}, \mathrm{Ge}$ ED, Fu YC (2015) Review and prospect of drilling technologies for carbon fiber reinforced polymer. Acta Materiae Compositae Sinica 32(2): 301-316. http://dx.doi.org/10.13801/j.cnki.fhclxb.201502 11.002

【 3 】 Ma LM, Zhang JZ, Yue GQ (2015) Application of composites in new generation of large civil aircraft. Acta Materiae Compositae Sinica 32(2): 317-322. http://dx.doi.org/10.13801/j.cnki.fhclxb.2015012 2.001

【4】 Liu XM, Sun HL, He LY (2018) Research status and development trend of CFRP drilling technology. Fiber reinforced plastics/Composites 03: 101-106.

【5】 Koplev A, Lystrup A, Vorm T (1983) The cutting process, chips, and cutting forces in machining CFRP. Composites 14(4): 371-376.

【6】Zhang L, Liu Z, TianW, LiaoW (2015) Experimental studies on the performance of different structure tools in drilling CFRP/Al alloy stacks. Int J Adv Manuf Technol 81: 241-251. https://doi.org/10.1007/s00170-015-6955-z

【7】 Qiu X, Li P, Niu Q, Chen A, Ouyang P, Li C, Ko TJ (2018) Influence of machining parameters and tool structure on cutting force and hole wall damage in drilling CFRP with stepped drills. Int J Adv Manuf Technol 97: 857-865. https://doi.org/10.1007/s00170-018-1981-2

【8】 Wang XD, Wang FJ, Li SK, Wang SF (2020) Research on variable parameter hole-making process of large thickness carbon fiber reinforced plastic. Journal of Dalian University of Technology 60(6): 591-598.

【9】 Wangyang N (2007) Orbital drilling of aerospace materials. Aircraft Structures. Beijing.

【 $10 】$ Qin XD, Chen SM, Liu WC (2009) Development and application of hole helical milling technology in aviation manufacturing assembly industry. Aeronautical Manufacturing Technology 06: 58-60.

【11】Wang Q, Wu Y, Li Y, Lu D, Bitoh T (2018) Proposal of a tilted helical milling technique for high-quality hole drilling of CFRP: analysis of hole surface finish. Int J Adv Manuf Technol 101: 
1041-1049. https://doi.org/10.1007/s00170-0171106-3

【12】 Sha ZH, Liu YF, Wu D, Zhang SF, Ma FJ, Liu Y (2018) Design of helical milling hole machining end effector and motion simulation analysis. MACHINE TOOL \& HYDRAULICS 46(13): 84-87.

【13】 Yang GL, Dong ZG, Kang RK (2020) Research progress of helical milling technology. Acta Aeronautica et Astronautica Sinica 41(7): 18-32.

http://hkxb.buaa.edu.cn/CN/10.7527/S10006893.2019.23311

【14】 Liao YP, Yan QY (1984) Application of Orthogonal Test Method in Machinery Industry. Beijing

【 15】 Jin LC, Yu J (2016) Multi-index optimization experiment design and application. Beijing 
Figures

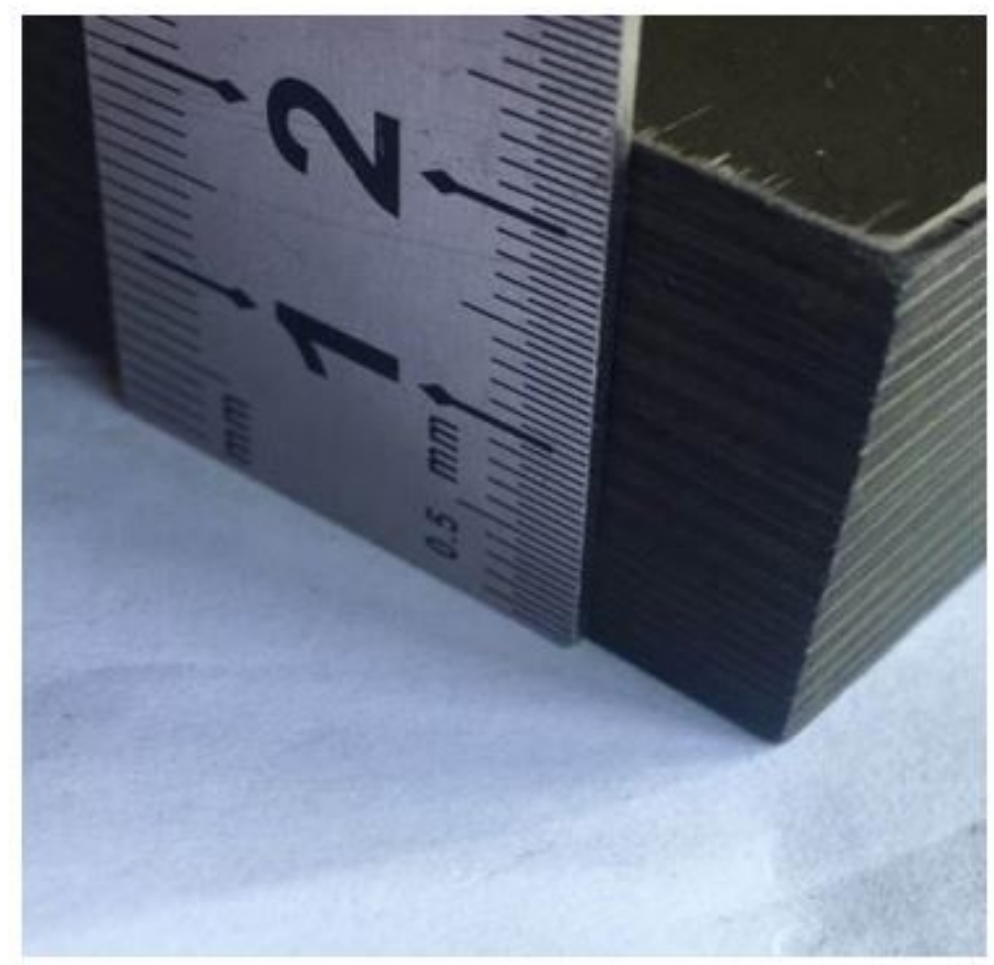

Figure 1

24mm CFRP material

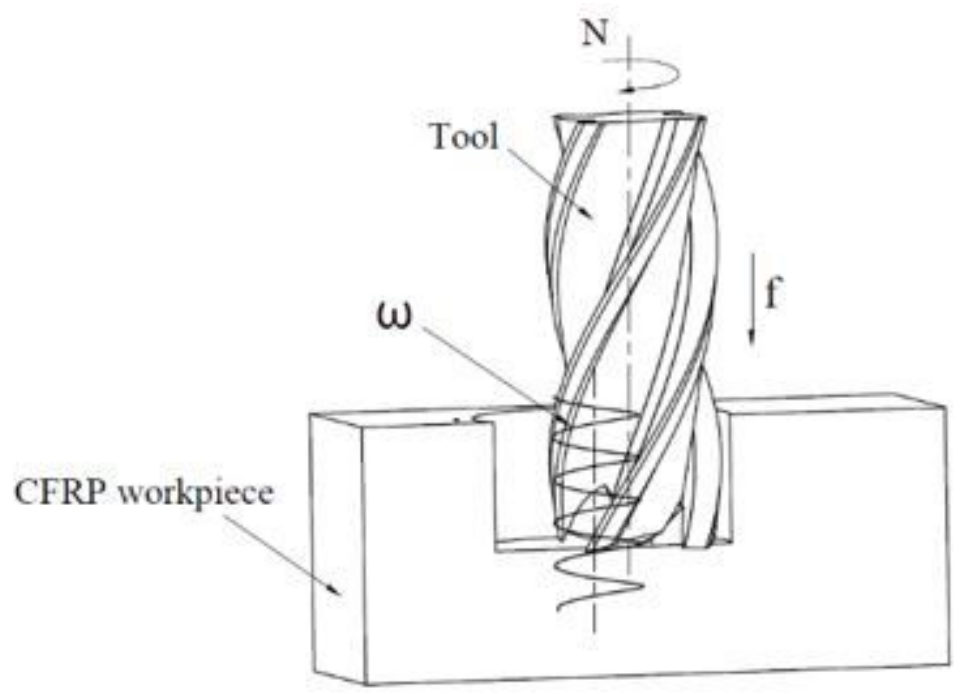

Figure 2

Schematic diagram of helical milling 


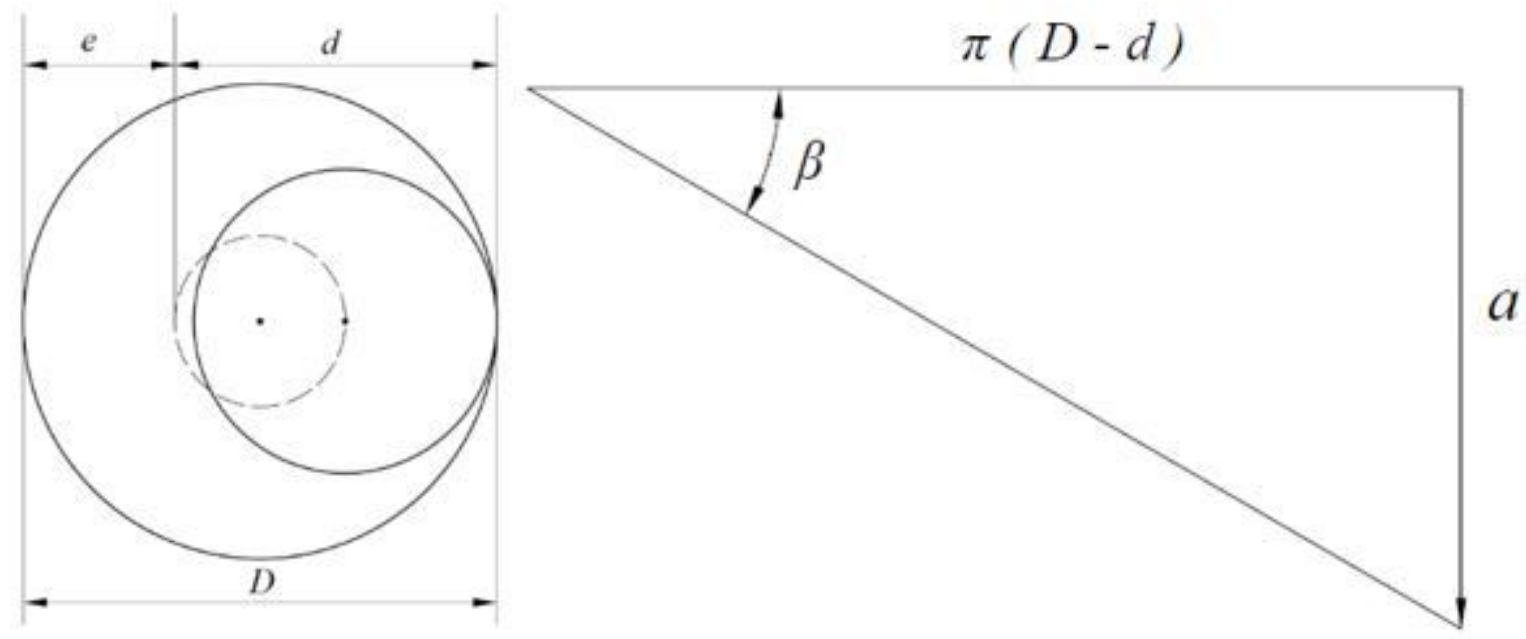

Figure 3

Plan schematic diagram

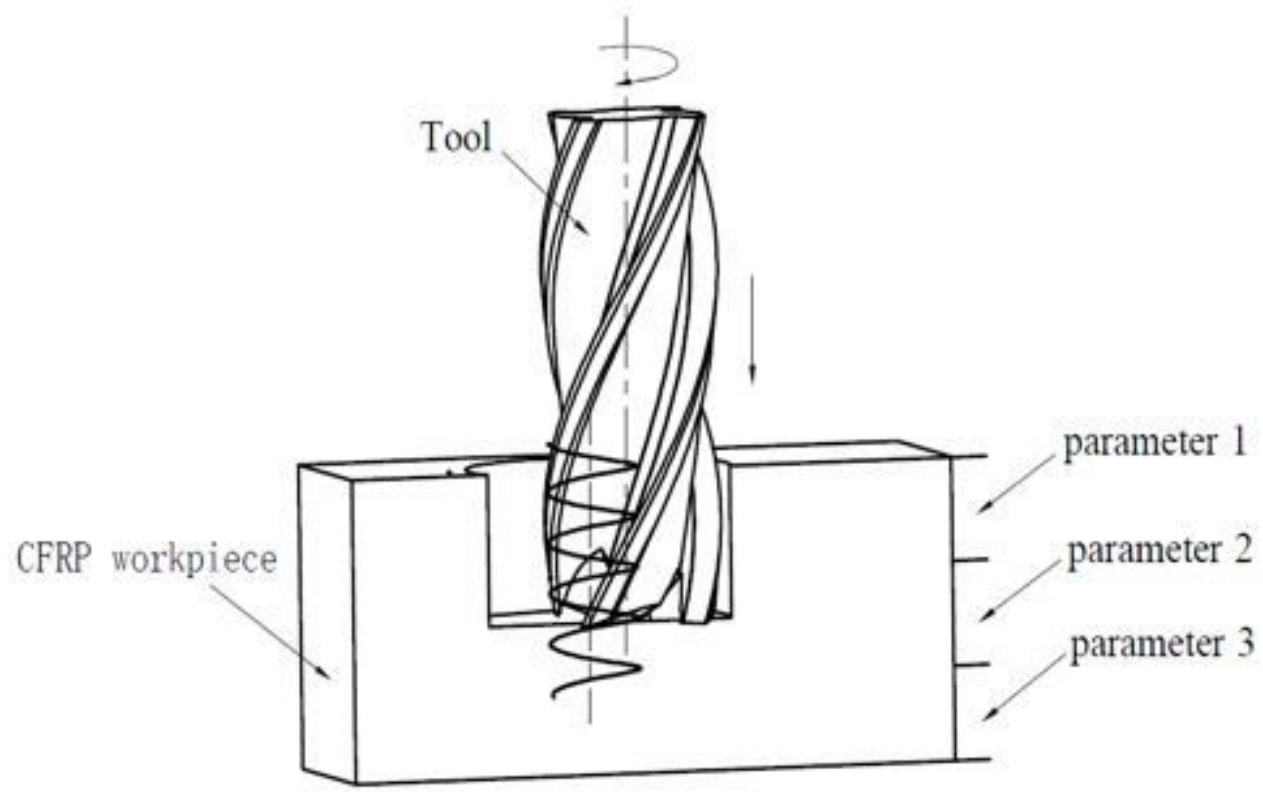

Figure 4

Schematic diagram of helical milling with various parameters 


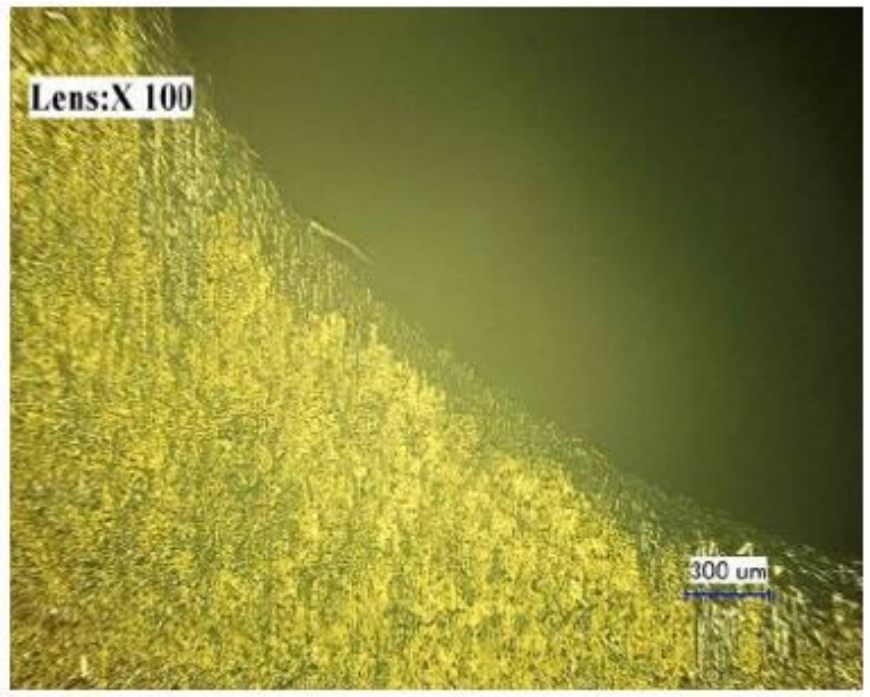

The entrance of the first set

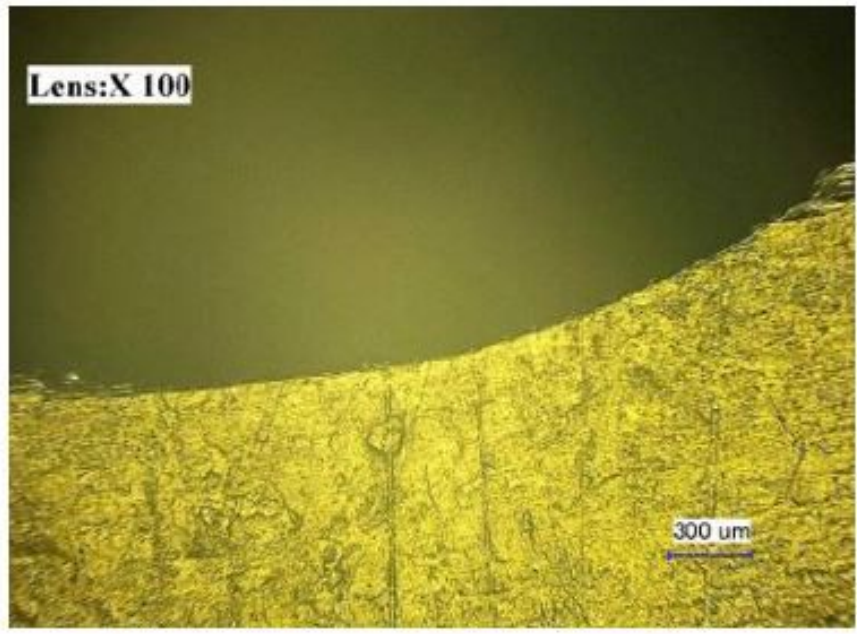

The outlet of the first set

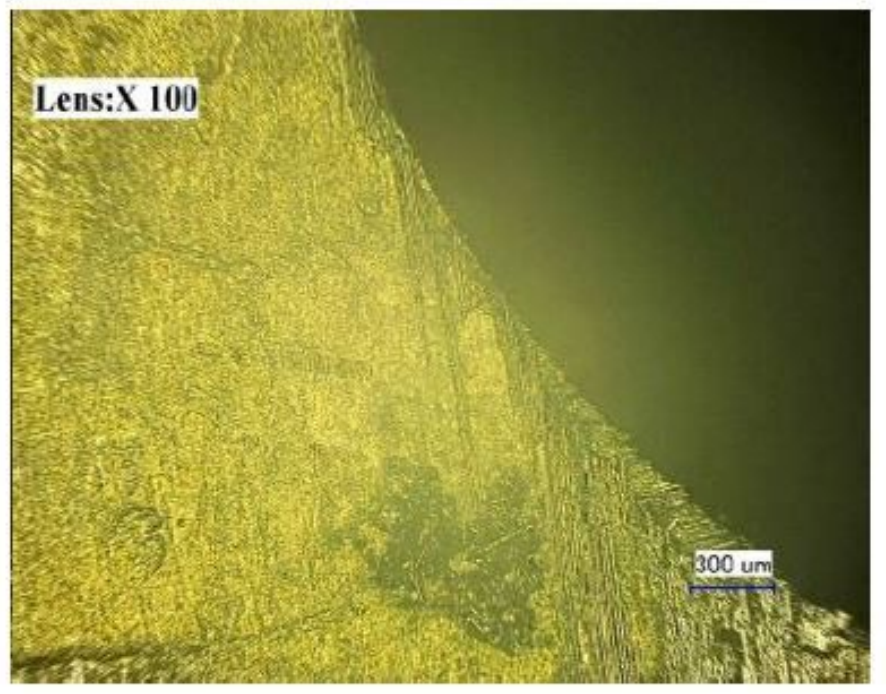

The entrance of the second set

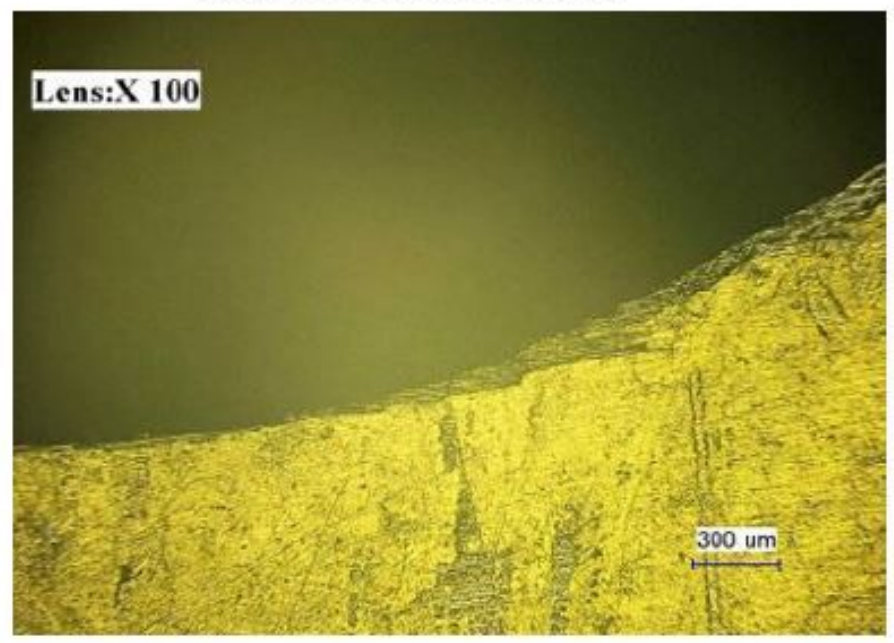

The outlet of the second set

\section{Figure 5}

The morphology of entrance and outlet 


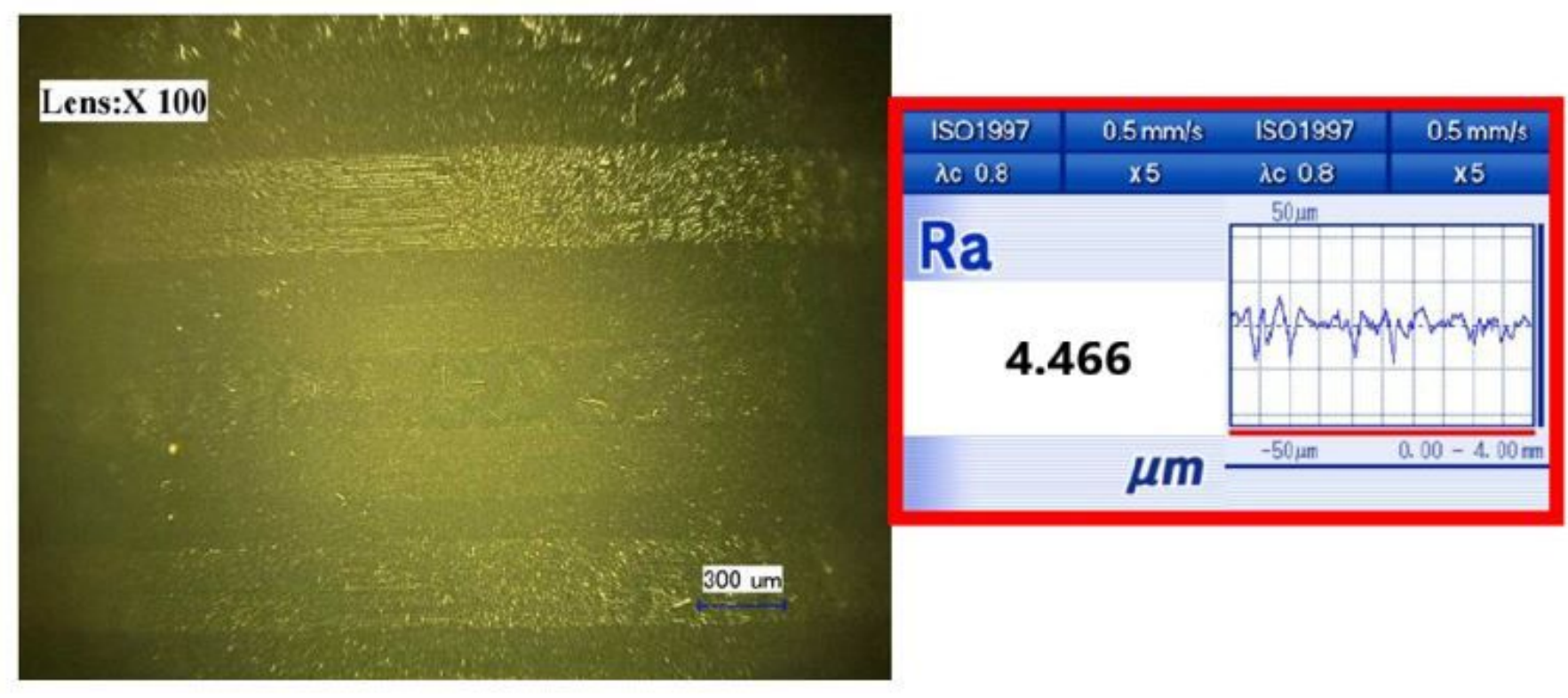

a. First set

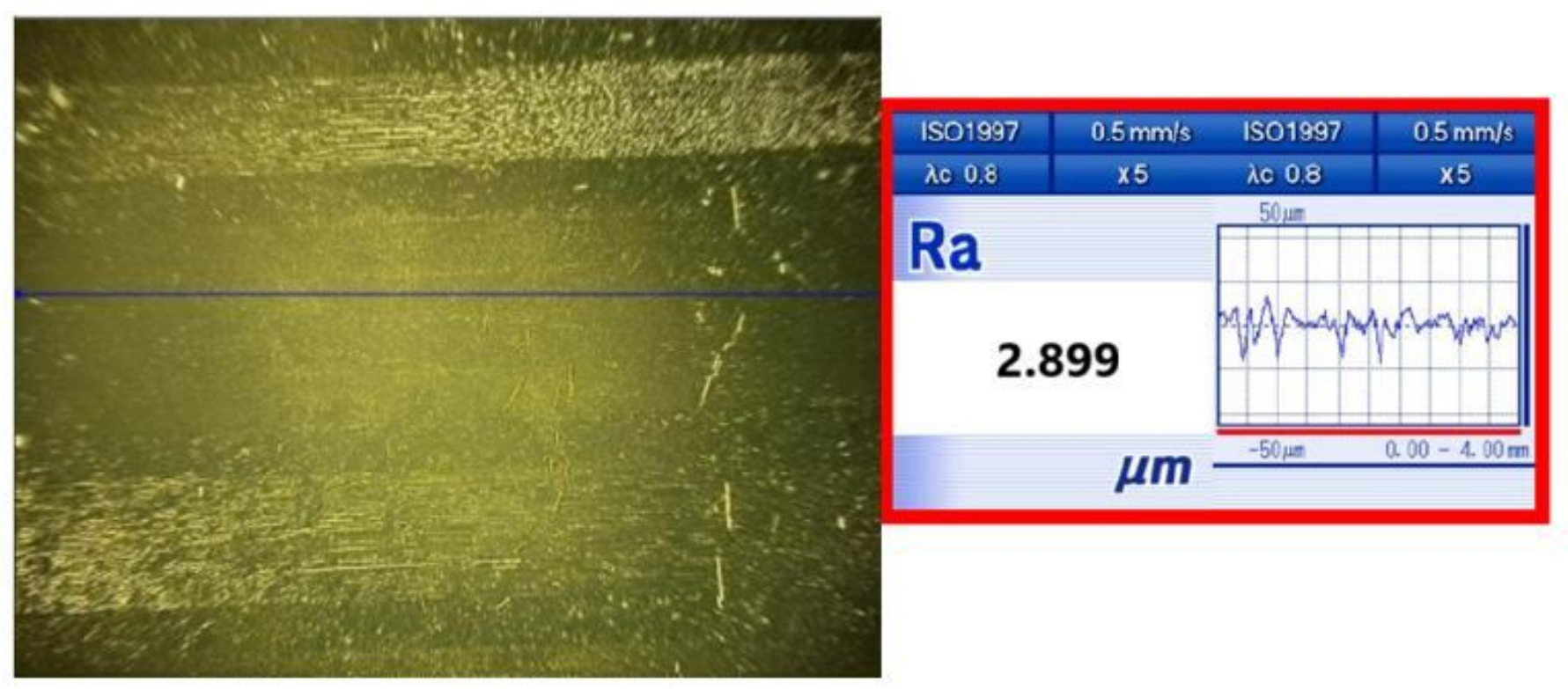

b. Second set

Figure 6

The curve of the hole wall morphology and surface roughness 


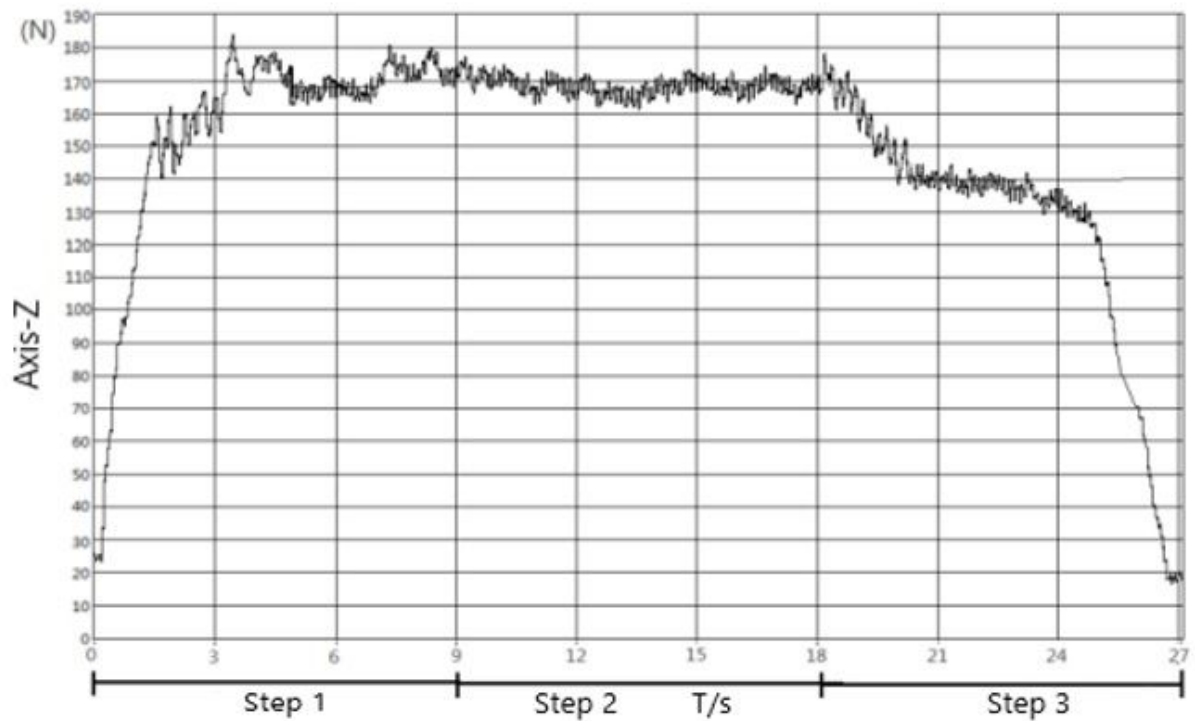

a. First set

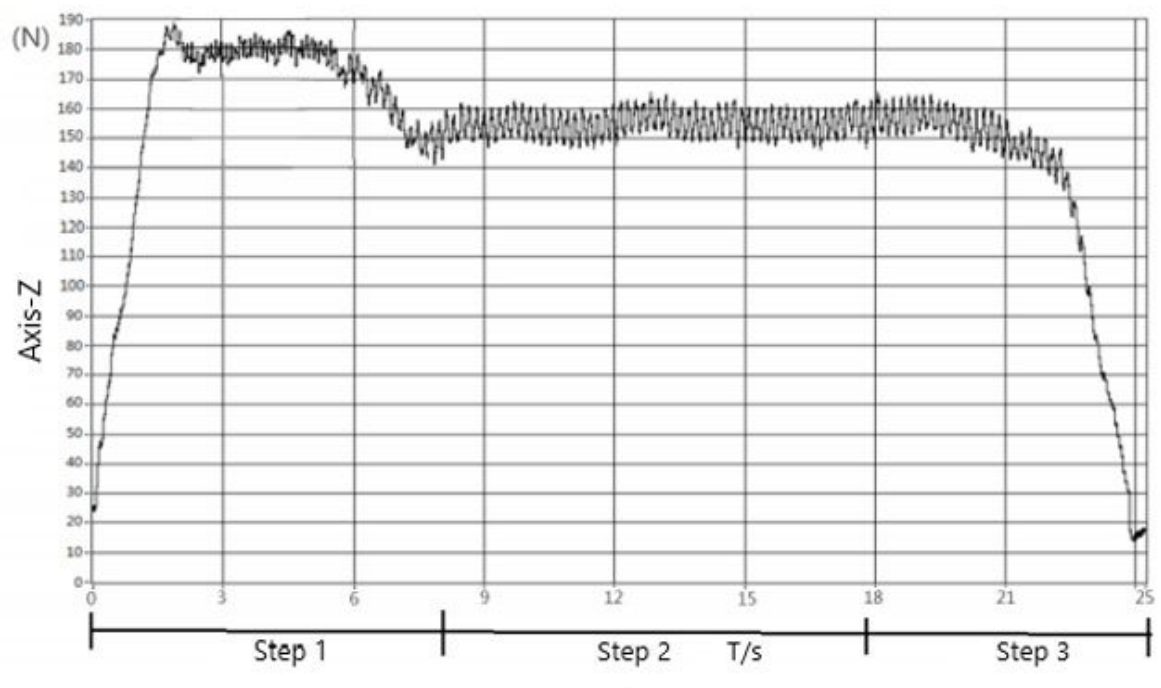

b. Second set

Figure 7

The curve of the axial force 


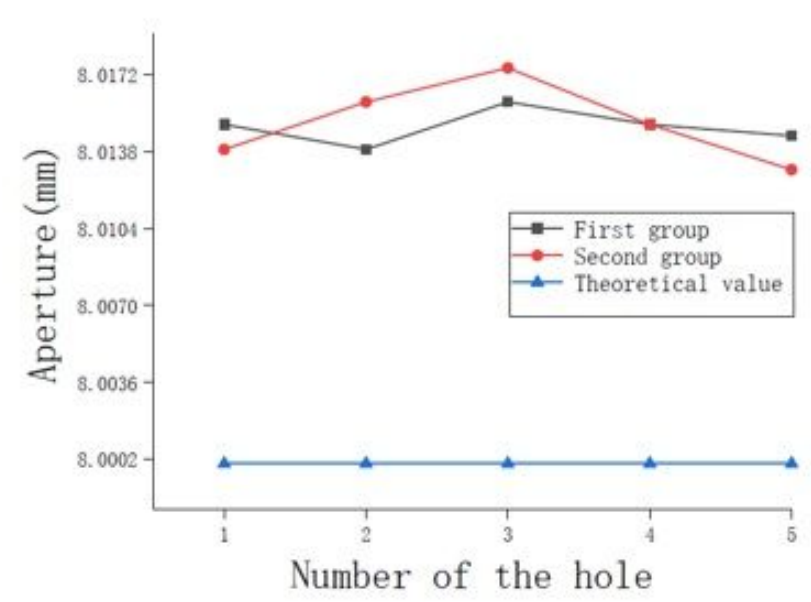

a. The entrance of the hole

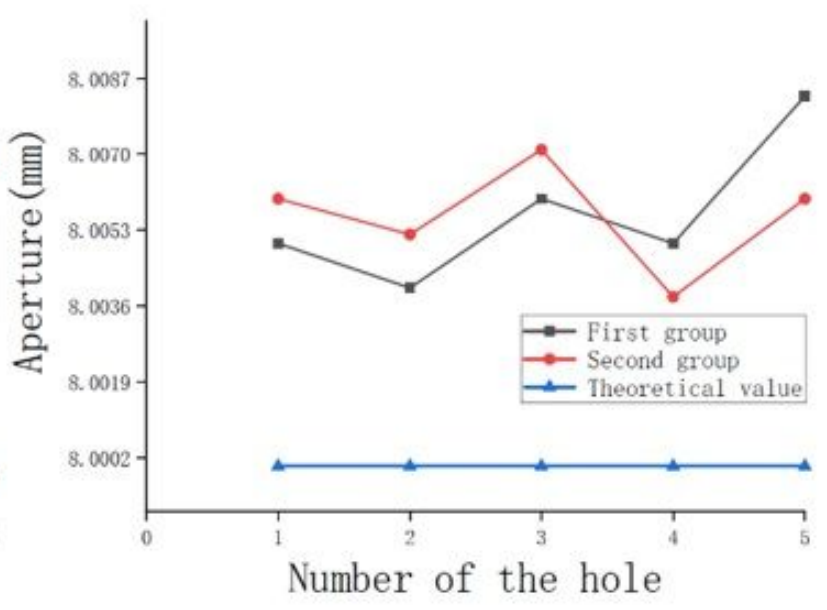

b. The outlet of the hole

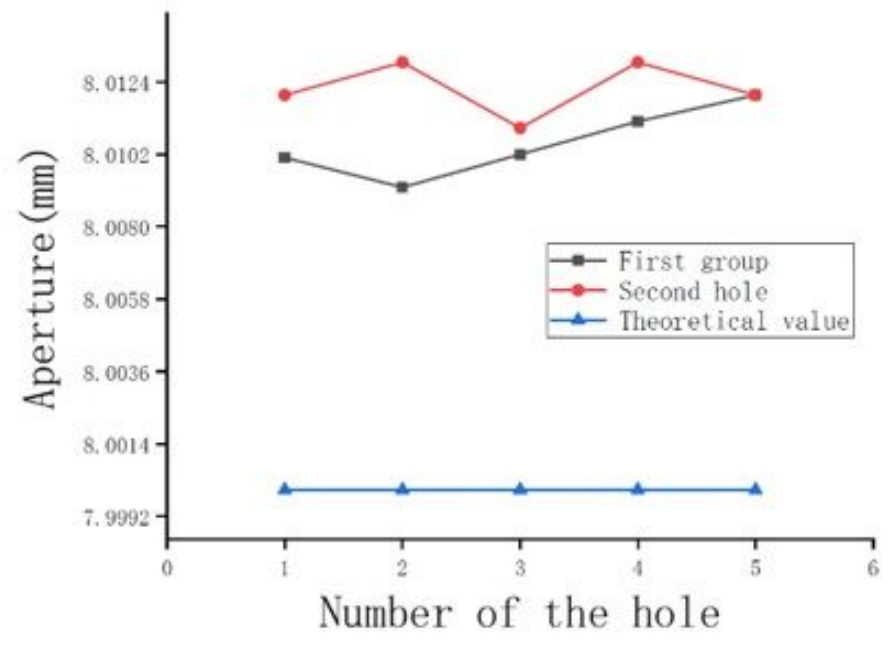

c. The middle of the hole

\section{Figure 8}

Pore size distribution diagram of step-by-step parameter hole making 


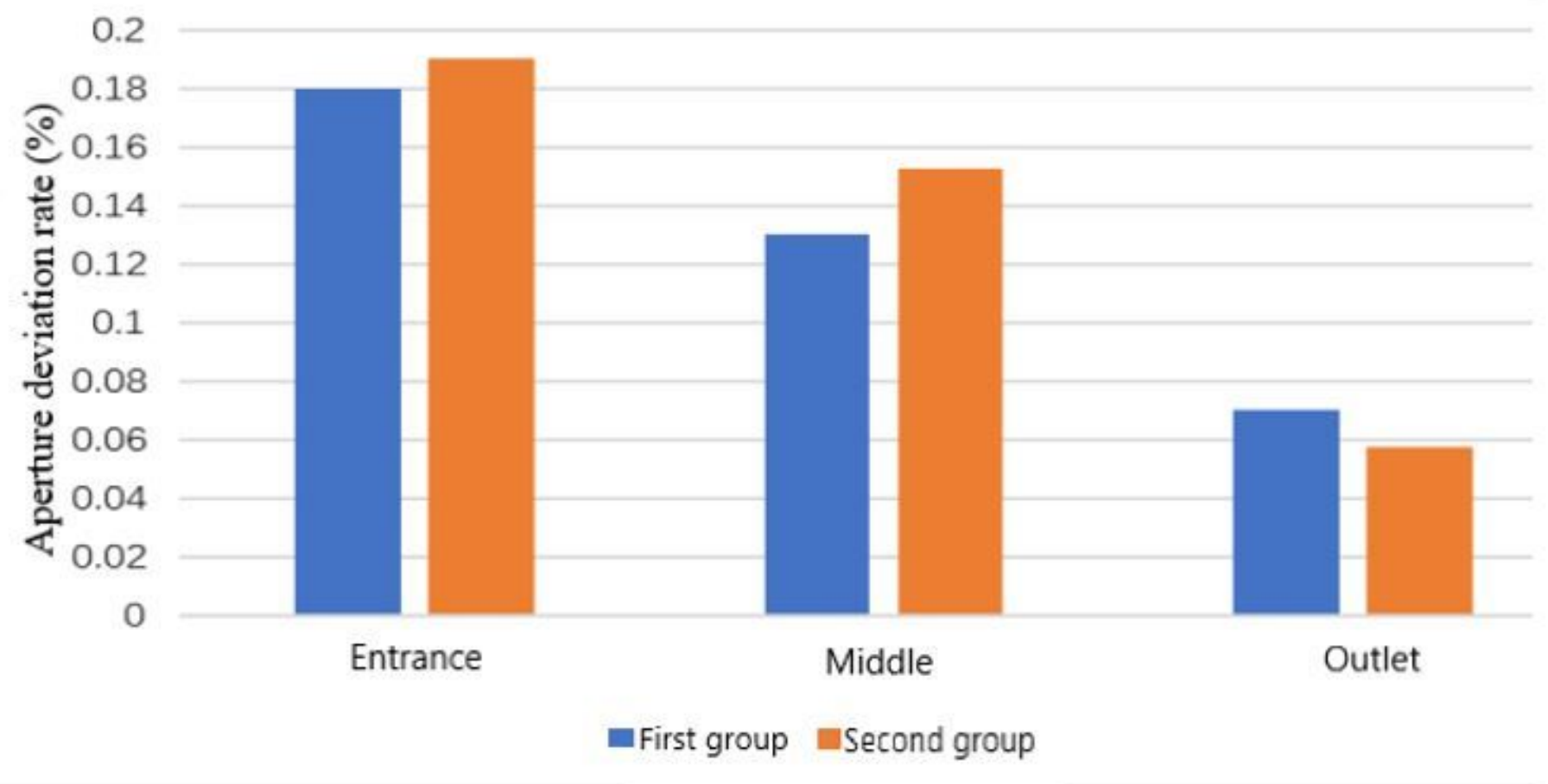

Figure 9

The histogram of the deviation rate of step-by-step hole making 